Florida International University FIU Digital Commons

FIU Electronic Theses and Dissertations

University Graduate School

3-30-2011

\title{
Community Environmental Preservation Initiatives in Borgne, Haiti
}

Craig J. Marcklinger

Florida International University, craig.marcklinger@gmail.com

DOI: $10.25148 /$ etd.FI1 1051008

Follow this and additional works at: https://digitalcommons.fiu.edu/etd

\section{Recommended Citation}

Marcklinger, Craig J., "Community Environmental Preservation Initiatives in Borgne, Haiti" (2011). FIU Electronic Theses and Dissertations. 403.

https://digitalcommons.fiu.edu/etd/403

This work is brought to you for free and open access by the University Graduate School at FIU Digital Commons. It has been accepted for inclusion in FIU Electronic Theses and Dissertations by an authorized administrator of FIU Digital Commons. For more information, please contact dcc@fiu.edu. 


\title{
FLORIDA INTERNATIONAL UNIVERSITY
}

Miami, Florida

\section{COMMUNITY ENVIRONMENTAL PRESERVATION INITIATIVES IN BORGNE, HAITI}

\author{
A thesis submitted in partial fulfillment of the \\ requirements for the degree of \\ MASTER OF ARTS \\ in \\ LATIN AMERICAN AND CARIBBEAN STUDIES \\ by \\ Craig Jon Marcklinger
}


To: Dean Kenneth Furton

College of Arts and Sciences

This thesis, written by Craig Jon Marcklinger, and entitled Community Environmental Preservation Initiatives in Borgne, Haiti, having been approved in respect to style and intellectual content, is referred to you for judgment.

We have read this thesis and recommend that it be approved.

Astrid Arrarás

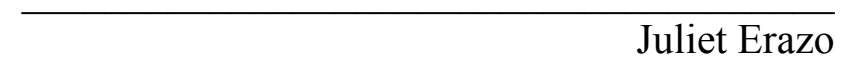

David Bray, Major Professor

Date of Defense: March 30, 2011

The thesis of Craig Jon Marcklinger is approved.

$\begin{array}{r}\begin{array}{r}\text { Dean Kenneth Furton } \\ \text { College of Arts and Sciences }\end{array} \\ \hline \begin{array}{l}\text { Interim Dean Kevin O'Shea } \\ \text { University Graduate School }\end{array}\end{array}$

Florida International University, 2011 


\section{ABSTRACT OF THE THESIS \\ COMMUNITY ENVIRONMENTAL PRESERVATION INITIATIVES \\ IN BORGNE, HAITI \\ by}

Craig Jon Marcklinger

Florida International University, 2011

Miami, Florida

Professor David Bray, Major Professor

The purpose of this thesis was to complete an analysis of the work and practices of the community organizations of Borgne, Haiti. While the work of several community organizations were examined, research specifically focused on the community's tree-planting project. Given the current state of Haiti's environment and the historic record of development efforts in Haiti, this project represents a unique model that may have larger implications on the way in trees are planted throughout Haiti. Field research was completed on site in Borgne in the summer months of 2010. The primary methods employed in data collection were Participatory Action Research and semi-structured interviewing. 


\section{TABLE OF CONTENTS}

CHAPTER

PAGE

I. Root Problem: An Explanation of Haiti's Environmental Issues...........1

II. The Exception not the Rule: Research in the Zone of Obòy..............19

III. Heads Together: Civil Society in Obòy..................................32

IV. Defending the Section: Local Initiatives in Action......................46

V. Trees for the Future: Moving Beyond Preserving Borgne's Trees..........59






\section{Chapter I: Root Problem: An Explanation of Haiti's Environmental Issues}

\section{Ia. Introduction}

By now it is largely cliché to cite the many factors that plague Haiti's chronic underdevelopment. Though Haiti is popularly cited as "the poorest country in the western hemisphere," this media cliché is of little use to most Haitianists as it fails to account for the complexities that characterize the countries grinding poverty. It is no secret that the puzzle of Haitian Development is complex and contains many pieces. One of the largest and most difficult pieces is the beleaguered Haitian environment, which has long been straining under the pressures of a growing population and low levels of development. Upon closer examination of Haiti's largely rural population, the interdependence between human and environment becomes tragically apparent. Environmental degradation and economic underdevelopment are both intrinsically tied to poor agricultural yields, depleted soil, and a near total absence of trees. Because only $2 \%$ of Haiti's tree cover remains, deforestation has caused massive erosion and soil degeneration (Homer-Dixon 1994, 34). Subsequently poor agricultural yields hinder the nation's ability to produce enough food to feed itself. Combining these conditions with peasant demands for energy threatens the Haitian environment's capacity to sustain a burgeoning population.

Though related to other pieces of the Haitian development puzzle, the question of mending the Haitian environment comes down largely to the best way trees can be incorporated into Haiti's existing agricultural systems while preserving those few tracts of forested land that remain (one of which is in the study location for this thesis). As with many challenges that hinder development in poorer nations, a 
litany of responses both governmental and non-governmental have been in place in many forms throughout Haiti. Though several NGOs claim to have "reforestation" projects that provide trees on some scale to the communities in which they work, the largest and most organized effort to respond to this challenge has been the Agroforestry Outreach Project (AOP). The AOP was a 20-year United States Agency for International Develop (USAID) funded venture that began in 1981 and continued under various names until 2000, providing trees to over 300,000 Haitian peasant households (Murray and Bannister 2004). While certainly the AOP was anthropologically successful (it won Applied Anthropology's Praxis Award in 1982), the debate about its success over the long term is still hotly contested. Though on a basic level Haiti is still almost wholly absent of trees, research continues as to the long-term success of the projects trees (Andrew Tarter is a Graduate student at the University of Florida who is completing his research on this, see Tarter 2009).

When viewed in the larger context of Haiti's development, the AOP represents a large well-funded effort that undertook a national issue by working through several large NGOs. While the project was well designed to incorporate social and economic dimensions on several levels (trees were distributed on the village level), its very presence is evidence of a largely ineffectual Haitian government that not only failed to reach out to its citizens but also wholly ignored its rural majority population (Murray and Bannister 2004: Maguire 2009). The decades long absence of any kind of government presence has not only created a "republic of foreign NGOs" that provide the bulk of Haiti's essential services but it has also had lasting social impact. The presence of dynamic community level organizations in 
Haiti, though born out of a need to overcome challenges in the absence of government help, may also reflect a more appropriate approach to development in Haiti. Though "grassroots" in itself has become a controversial buzzword on the development scene, it is evident that rural Haitians are more than capable of mobilizing themselves toward a cause (Smith 2001). It is of little surprise then that some of these organizations have moved beyond the often-cited konbit (a Kreyòl word describing collective farm work) to larger endeavors — such as tree planting, environmental education and erosion control.

One example of such a mobilization to stop further environmental destruction is the case of community organizations of the town of Borgne (Obòy in Kreyòl). Borgne, situated on Haiti's northern coast about 30 miles West of Cap-Haitien, is home to the Mouvement Developpement Integral Borgne (Movement for the Integral Development of Borgne-MODEIB) and the Organizasyon Gwoupman Peyizan Kot de Fer (the Gwoupman Peasant Organization of Kot de Fer-OGPK), who have in recent years undertaken a tree-planting and education initiatives in the commune. While their work is decidedly important for their own community, which still retains significant tracts of forested land, it may have even larger implications throughout the island. The purpose of this thesis will be to complete an analysis of the work of these organizations and their practices. A review of works related to both tree planting in Haiti and community organizations better illustrates the importance of this study.

\section{Ib. Review of Literature - Where does it all fit in?}

Most successful endeavors incorporate multi-faceted approach that crosses a range of disciplines and balances both technical skills and social understanding. 
Though I will explain my research approach more explicitly below, suffice it to say that the literature summarized and reviewed below is a mélange of both social and environmental science. This is intended to reflect the aforementioned balanced and multi-disciplinary spirit of this study.

Germane to this study is an understanding of the ideas and practices of agroforestry. Though harnessing the power of trees to combat the myriad environmental problems facing farmers in developing countries seems simple enough, the layered implications of a project that provides trees must be considered on a deeper level. One technique that has developed to combat these issues is agroforestry, or "on-farm tree establishment and management" (Current et al 1995: xi). In the same vein as the eclectic nature of this study, agroforestry reflects the social, economic and environmental needs of the farmer.

Agroforestry does not involve the traditional idea of reforestation; instead it draws some aspects of forestry and incorporates them into agricultural practices. More specifically defined it is "The deliberate use of woody perennials (trees, shrubs, palms, bamboos) on the same land management unit as agricultural crops, pastures, and animals. This may consist of a mixed spatial arrangement in the same place at the same time, or a sequence over time" (Current et al 1995: xviii). This involves a variety of specific techniques that are aimed at improving the farmers land, yields, or providing economic benefits either directly (through tree products) or indirectly through less tangible methods, aiming overall land improvement.

On a general level, projects that aimed at simply providing fuel wood to communities evoked little interest from farmers, probably because in most cases 
(Haiti is a notable exception) the production of fuel wood is a labor-intensive process that tends not to garner much income at market. Thus, agroforestry practices have evolved to move beyond simply providing trees for fuel wood and instead focus on multi-purpose tree species (MPTS) that supply "green manure, wood for construction needs, fence posts, and fuel and raw materials for local or industrial processing" (Current et al 1995: 2). Additionally, trees can act as a savings bank of sorts by where incomes can be supplemented by felling trees during times of extreme need or when crop yields are poor. Similar to the economic role of livestock among rural farmers, Murray and Bannister found that with AOP project trees in Haiti, farmers "used the tree to store value, [as they are] less vulnerable to drought than annual crops." Further, "under such conditions of agrarian peril the domestic tree stand becomes an economic safety net that is protected until absolutely needed, and even then cut only sparingly" (Murray and Bannister 2004: 388).

Although the benefits that come with the presence of trees are diverse and numerous, a natural conflict may still be present with crops already present in the agricultural system. Many specific techniques have sought to ameliorate this competition by integrating tree species into farming systems with a minimal impact on or added benefit to overall farm productivity. While the economic benefits of felling trees in a time of need can often be counted in cash, the longer-term benefits are much harder to trace and yet offer arguably equivalent benefits on both the individual and community level. These benefits include:

(a) protection from water and wind-generated soil erosion, thus protection from the future productive potential of the land as well as important 
watersheds that feed hydroelectric projects and supply water for population centers; (b) provision of a source of wood products on-farm, thus protecting natural forest areas from continued degradation and deforestation; (c) provision of raw materials for rural industries that generate employment in the local communities; and (d) other environmental and social benefits. (Current et al 1995: 2)

The long-term impact of these various benefits is important and while it might ultimately improve crop yields, of particularly interest to this study is the final listed benefit “(d) other environmental and social benefits." This study will seek to contextualize and explain some of these benefits while simultaneously giving credit to the ecological and economic benefits that trees provide in and of themselves.

Finally, though not necessarily precise in terms of the techniques observed during research in Borgne, the general agroforestry techniques that are relevant to this study are described below (developed from the glossary of Current et al 1995: xviii). Ally cropping: Cultivation of annual crops between rows of trees or hedgerows. Sometimes called hedgerow intercropping. Boundary Planting: Lines of multipurpose trees or shrubs planted along borderlines and boundaries dividing properties or land uses.

Living Fences: Using living trees rather than dead posts, as fence posts. In Central America [in Haiti as well], these are usually used to support barbed wire fencing. The fence posts may be also be managed for fuel wood or poles. 
Taungya: A system in which new forest plantations are established together with food and cash crops, which continue to be intercropped until shaded out by maturing plantation.

Windbreak: Strips of trees or shrubs planted to protect fields, homes, canals or other areas from wind and blowing soil or sand.

It is worth noting that Current et al. (1995) found that "There were no single agroforestry systems (ally cropping, homegardens, taungya, etc) that consistently outperformed the others across projects" (8-9).

Also of primary relevance to this study is an understanding of the broadest and most robust effort to plant trees in Haiti. In their article on the 20-year USAID funded Agroforestry Outreach Project (AOP), Gerald Murray, an anthropologist, and Michael Bannister, an agroforester, discuss the project design and emerging lessons from their experience with the project (Murray and Bannister 2004). The AOP was implemented under the auspices of a heavily combined anthropological and agroforestry based approach (Murray and Bannister 2004: 383). This approach, which was born out of the failure of past projects that began in haste after World War II, is characterized by several key factors, which remain germane to tree-planting projects in Haiti. Where past projects worked through the bureaucratic and corrupt Haitian government, focusing on conservation and "reforestation" efforts, the AOP was fiscally managed through NGOs and focused instead on incorporating trees into the existing agricultural systems of the densely populated island. Further, Murray isolates the role of trees as a safety net for the peasantry, who fell trees to produce charcoal that can be sold when agricultural yields are poor. While this charcoal 
industry provides energy to the majority of the population, who do not have access to electricity, it is the same industry that continues to threaten Haiti's few remaining trees. Thus, the AOP approached the role of the tree not as an ecological entity to be preserved but as a crop that should be harvested as an economic venture. In total, the AOP reached over 300,000 rural peasant families and provided millions of fast growing wood trees and/or hedgerows (Murray and Bannister 2004: 383).

While the whole of the project and subsequent research that has resulted from the AOP is of general relevance to anyone hoping to research or plant trees in Haiti, there are several observations and lessons from the project that are of particular relevance to this thesis. First and foremost is the basic understanding of the role of trees in Haiti's agricultural system. Because of the dense population, trees in Haiti must exist not as forests but rather as useful tools to aid Haiti's rural farmers. Whether this is purely economic or instead related to soil conservation or other similar techniques for protecting land or increasing yields, the authors provide the lessons and background necessary for understanding trees. Of specific importance to this study is Murray and Bannister's observation that professionally run nurseries produce more trees than so called "backyard nurseries" which they claim produce fewer seedlings (Murray and Bannister 2004: 395). Their findings will need to be measured against the peasant initiatives in Borgne- both in terms of rates of seed production, survival rate and financial savvy.

In one of the first deep reviews of the Agroforestry Outreach Project, Balzano (1986) examines the "Socioeconomic Aspects of Agroforestry in Rural Haiti", exploring the AOP's impact on two communities on Haiti's southern peninsula. The 
author takes a multidisciplinary approach but importantly moves beyond mere analysis of the applied anthropological processes in implementing the project to surveying the experience of the AOP participant in those communities. In contrast to other pieces, this paper gets into the tangible practices of the both the AOP and the rural Haitian cultivator; from the role of community level tree distributors (animatè) and local organizations to the way the project fits into traditional agroforestry systems and the rural agricultural economy. On an even simpler level, the definition of a "planter" as well as a review of locally cultivated crops is provided. Though specialized to the case communities in the report, field experience indicates that many of the species discussed are grown throughout rural Haiti. Finally, the author provides a rich list of recommendations, many of which call for incorporation of socioeconomic factors and further research on the impacts of the project.

Perhaps of greatest importance to this thesis, beyond the basic descriptions of the functions of the AOP that are provided, are the aforementioned recommendations, which call for the integration of socioeconomic factors into future AOP activities. Though prior to my field research, I thought the tree-planting project of Borgne was developed independently of the AOP or other foreign organizations, my earliest field observations indicated that the primary steward and designer of the project in Borgne was a Pan American Development Foundation (PADF)-trained animatè, who was heavily involved with the AOP in Borgne in the late 1980s. Like all animatè, the designer (who has also served in several capacities with the local organizations of Borgne) was trained by the PADF in basic agroforestry extension skills. In this context then, the tree-planting activities in Borgne can be viewed-at least in part- 
as an extension of AOP, or as a long-term societal impact. Though 20 plus years removed, the Borgne project is partly a manifestation of Balzano's largest recommendation, which was to localize tree-planting efforts so that they might "be wholly integrated and geared toward dealing with local circumstances and the wide variety of environmental and economic conditions existing in rural Haiti" (Balzano 1986: 41). The idea of the localization of a national project will be an important theme and will be explored further throughout this thesis.

Shifting both gears and locales, Jickling and White (1995) survey land use, agricultural systems and the costs and benefits of agroforestry adoption in two communities in rural Haiti. After surveying agroforestry projects in Haiti (including the previously mentioned AOP), the authors focus on the several methods by which landholders incorporate trees into their agricultural systems. These range from home tree gardens or jaden lakou to border systems, living fences, dispersed intercropping as well as rak bwa or woodlots, pastures and fallow lands. The authors then delve into their analysis of two separate agroforestry projects. The first of which was managed by the Pan American Foundation (PADF) in Maniche, on Haiti's southern peninsula and the second, which was managed by the Save the Children Foundation (SCF) in the community of Maissade in Haiti's Central Plateau. Though the findings for each varied slightly because of differing climates, the authors primary conclusions are that while agroforestry practices (particularly indigenous practices) are generally beneficial to the farmer in terms of garnering additional cash, their greatest benefit is in the "store of value" as trees are quickly and easily converted to raw capital (Jickling and White 1995: 192). Also, the authors believe that while it is attractive 
for both donors and peasants to invest in trees, investments in agriculture are likely much more beneficial in improving the livelihoods of rural Haitian farmers (Jickling and White 1995: 192).

In examining the authors findings, one major contribution is that it offers explanation for the financial benefit of trees while candidly concluding that trees are but one part of Haiti's agricultural system. Further, the author's classification of various types of agroforestry and the tree-use practices present in rural agricultural systems is certainly of great benefit. Another issue the authors discuss is the likelihood of agroforestry adoption based on class or income level. Though this is commonly a problem for farmers in adopting new technology (poorer farmers cannot afford to take risks), it is important to note that that it also carries over to tree planting initiatives. While my research does not overly focus on improved economic conditions based on the presence of trees, the model and findings provided are important in situating the role of agroforestry systems for the rural Haitian farmer.

In addition to White and Jickling's more technical analysis of agroforestry systems, White and Runge (1995) also offer a great deal of insight into the role of collective action in their study on the participation in the adoption of check dams in Haiti's Central Plateau. Their discussion is decidedly applicable to this thesis as the phenomenon at play in Borgne certainly warrants analysis through the "collective action" framework. Excluding other factors, White and Runge conclude that the primary motivational factors influencing "Individual choice to cooperate in collective actions that yield public goods" were "prior membership in reciprocating social organizations; practical knowledge of potential gains from cooperation; and some 
potential to gain from that action" (White and Runge 1995: 1690). The dominant "reciprocating social organizations" were gwoupman and the reciprocation came in the form of shared labor arrangements. Further, the authors conclude that a general expectation of participation existed with in the community and while Haitian's may not necessarily be "categorically cooperative," the "existence of such expectations suggests that this rural culture embodied a moral economy entailing norms of solidarity and reciprocity" (White and Runge 1995: 1690-91). Given the presence of active community organizations in Borgne (as in the study, the gwoupman model is also dominant in Borgne) and the population's extensive knowledge of the value of their trees (Borgne's culture of environmentalism will be addressed below), the current tree-planting project also illustrates the incorporation of indigenous knowledge as is discussed in Jickling and White (1995). Jickling and White note the success of projects that did not bring in external ideas on agroforestry but instead "were successful because they complemented indigenous techniques and the historical trend of tree domestication in Haiti" (Jickling and White 1995: 9).

Combining all of these factors, it seems that the current work of the organizations of Borgne, and their NGO partners has successfully teased out the factors that make up an appropriate model of "grassroots development." This technique can be defined as "the collective action of the poor to solve their problems with modest infusions of external support" (Bray 2009: 9). The project and the combined factors at play also makes a case for Hirschman's idea of "Social Energy" which Bray describes as existing "somewhere between that of 'human capital,' meaning knowledge, and that of 'social capital,' personal networks that can be used 
for economic advancement" (Bray 2009: 6). Thus, the successful actions of the organizations of Borgne, as well as their specific desire to engage in agroforestry through collective action is supported by the findings of White, Jickling and Runge. Considering that these factors can be taken from the larger context of the literature and viewed in practice in Borgne, gives credence to the reflection of the grassroots values that are lacking within the larger scope of development efforts (Bray 2009: 3). Moving away from trees specifically and focusing on what has now largely become a classic methodology for grassroots organizations and agricultural extensionists, Bunch's (1998) "People-Centered Agricultural Development" technique focuses on participatory development and increasing agricultural yields through a series of adaptable core principals. The basics of these principals are 1) to teach farmers to experiment with new technologies on a small scale, 2) use rapidly viewed success to motivate farmers to continue innovation, 3) use technologies that use local and inexpensive resources, 4) begin by using a small number of technologies and finally 5) train local leaders as extensionists and support teach other farmers, thus spreading the technology (Bunch 1998). Bunch's approach is predicated on the idea that many large NGOs don't often work on a people-to-people or farmer-to-farmer level. Additionally, he cites many of the techniques being used in development practices are those being exported from industrial countries and were developed after those nations were economically advanced. Thus the technology in use is not appropriate for farmers in developing nations that lack the resources of farmers in the developed world. 
Despite begin designed for a more agricultural based study, the core principals of Bunch's "Two Ears of Corn" approach are applicable in many parts of the field of development. It is the primary aim of this study to use Bunch's general approach if not his actual principals in facilitating research that will benefit the organizations and practices under study. The very nature of the organizations in Borgne and peasant organizations in Haiti in general is a people-to-people approach by which success and knowledge can be transmitted to others. Specifically, Bunch's approach allows for adjustment to a non-Western setting by where one can gain the rapport necessary to conduct effective research. This is done through simple activities such as taking the 'time to do such things as walk through a villagers' fields, send[ing] them a note of appreciation, enjoy[ing] a meal in their homes, or play[ing] a while with their children" (Bunch 1982: 74). It should be noted however that while Bunch's ideas and principles are important in general application, he gives little credit to the capabilities of preexisting organizations within a community. Bunch notes that "With constant innovation, new needs and new opportunities will present themselves. These will often best be seized or solved not through some preexisting structure, but by new organizations...that people will create if and when they are needed" (Bunch 1998: 149). Unlike Jickling and White, Bunch puts little faith in indigenous knowledge, instead emphasizing the importance of "contacts with outside sources of information and support" (Bunch 1998: 149). Thus while the cultural sensitivity and peoplecentered approach that Bunch espouses was applicable for designing and implementing research in rural Haiti, not allotting space for collective action through 
community organizations means Bunch is of limited use to a major academic part of this thesis.

\section{Ic. Conclusions on the Literature}

As the above scholarship illustrates, tree-planting efforts in Haiti is hardly a new endeavor and given Haiti's current state in terms of forest cover, much work is left to be done. Haiti has long been subjected to large projects designed and implemented by various Northern countries or Bretton Woods institutions. While these projects no doubt had the best intentions, they represent a definitively top-down approach that does not necessarily account for the needs of the rural Haitian farmer. The above-described Agroforestry Outreach Project, though incorporating applied anthropology and using extension agents that provided trees at the household level, does not necessarily represent a definitive grassroots approach. In his analysis of the AOP, Balzano (1986) sets up the context for the long term implications of the AOP that are reflected within the current project in Borgne. Further, while previous studies have explored the implications of agroforestry, the infusion of indigenous knowledge into projects and the likelihood of project adoption by individuals through collective action, gwoupman and community organizations are considered only tangentially, rather than as key drivers of community development (White and Runge 1995: White and Jickling 1995). Therefore, it is within the broad range of approaches explored above that I hope to situate my research, examining the implications of a definitively different approach to trees that begins not necessarily with a robust foreign NGO but rather with the well-organized peasant organizations of rural Haiti. 


\section{Id. The Objectives of this Study}

The primary objective of this thesis is to conduct an ethnographic assessment of the NGO-led community tree planning initiatives in Borgne, Haiti. Through participatory action research and semi structured interviewing, the grassroots organizations involved in providing trees to local farmers as well as preserving and regenerating the forested environment around the commune of Borgne, were surveyed. This thesis will examine the origins, history, and current project implementation strategies and methods of the organizations involved, specifically the Mouvement Developpement Integral Borgne (Movement for the Integral Development of Borgne-MODEIB) and the Organizasyon Gwoupman Peyizan Kot de Fer (the Gwoupman Peasant Organization of Kot de Fer-OGPK), who have undertaken a tree-planting, protection and education initiative in recent years. It will also suggest some tentative proposals for why this effort at collective action has survived for so long and continues today.

Community tree planting and environmental preservation efforts in Borgne are also of particular interest because of the noted historical efforts of international nongovernmental organizations, with bilateral funding, to attempt to "reforest" or undertake large-scale tree-planting initiatives in Haiti. While larger projects have been undertaken in the past, the possibility of organizational success at the commune level is promising for future efforts to halt environmental degradation in Haiti through tree-planting initiatives.

With these facts in mind, this thesis will further seek to understand the methodology of Borgne's community organizations in developing a multi-pronged initiative to combat environmental degradation. In further explaining their current 
actions, the decision of the community to form an organization and act to prevent further environmental damage in the commune through providing trees and education to community members will be dissected. The majority of this information has been derived through participatory action research with the aforementioned community organizations and semi-formal interviews with local community members.

\section{Ie. Structure of this Thesis}

Chapter I of this thesis has introduced the concepts and relevant literature related to tree-planting initiatives in Haiti. It has further explained their relevance to this study so that the research that follows can be properly situated among the existing and currently developing work in this field.

Chapter II of this study will introduce the research location for this thesis as well as isolate and explain some of the unique and distinguishing characteristics that make up the geographic and civic identity of Borgne. It will further discuss the unique culture present in Borgne and why it necessitated the research methodology that was employed in the production of this study.

Chapter III will introduce the civil society present in rural Haiti and how such an advanced and dynamic structure developed. It will then specifically profile the community organizations at work in Borgne - focusing on their history, explaining how they came to be, their current work and the significance of that work. It will also discuss the NGOs at work in Borgne as well as their respective development models.

Chapter IV will profile the current tree-planting project in Borgne that is the primary subject of this thesis. The factors that produced the project will be discussed 
as well as tangible practices, species employed by the project and way in which trees are distributed and monitored in the community.

Chapter V will focus on a deeper analysis of the work of the organizations in Borgne, discussing their tree-planting efforts, the "success" of the project and it's role in civic and cultural preservation. Finally, it will examine the idea of the project as a model as well as the greater implications that the project might have throughout Haiti. 


\section{Chapter II: The Exception not the Rule: Research in the Zone of Obòy}

\section{IIa. Location}

The primary research location for this study was the community of Borgne (Obòy in Kreyòl), located on Haiti's northern coast about 30 miles west of CapHaïtien, the country's second largest city. Slightly smaller than the U.S. State of Maryland, Haiti covers the western third of the island of Hispaniola, which it shares with the Dominican Republic. Haiti’s population is approximately 10 million with over $2 / 3$ of that population engaged in some sort of agricultural endeavor. Though most of the population relies on subsistence agriculture and remittances (which make up nearly $20 \%$ of the GDP), export commodities include apparel, fine oils, cocoa, mangos and coffee (World Factbook). Borgne is a small-scale agricultural and fishing community that has an estimated population of about 80,000 people (H.O.P.E nd).

The large rugged mountains that are typical of Haiti characterize the physical geography of Borgne and the surrounding community. The town center is situated on a small peninsula that is bordered on the east by a small bay and the west by two small rivers that adjoin just south of the town center and flow as one larger river into the sea. Beyond this larger river to the west is an area known as Osab (or "sand" in Kreyòl) is a large group of family structures that is situated between a long beach that runs East-West and a large agricultural plain that runs up into the foothills of the mountains. The agricultural area is a complex puzzle of plots that are connected through a series of footpaths. Dozens of varieties of crops are grown, from sugar 
cane to corn, rice, plantains, bananas and mangos. These are typical of Haitian agricultural production and comparable to those discussed in the previously reviewed Balzano article (Balzano 1986: 10).

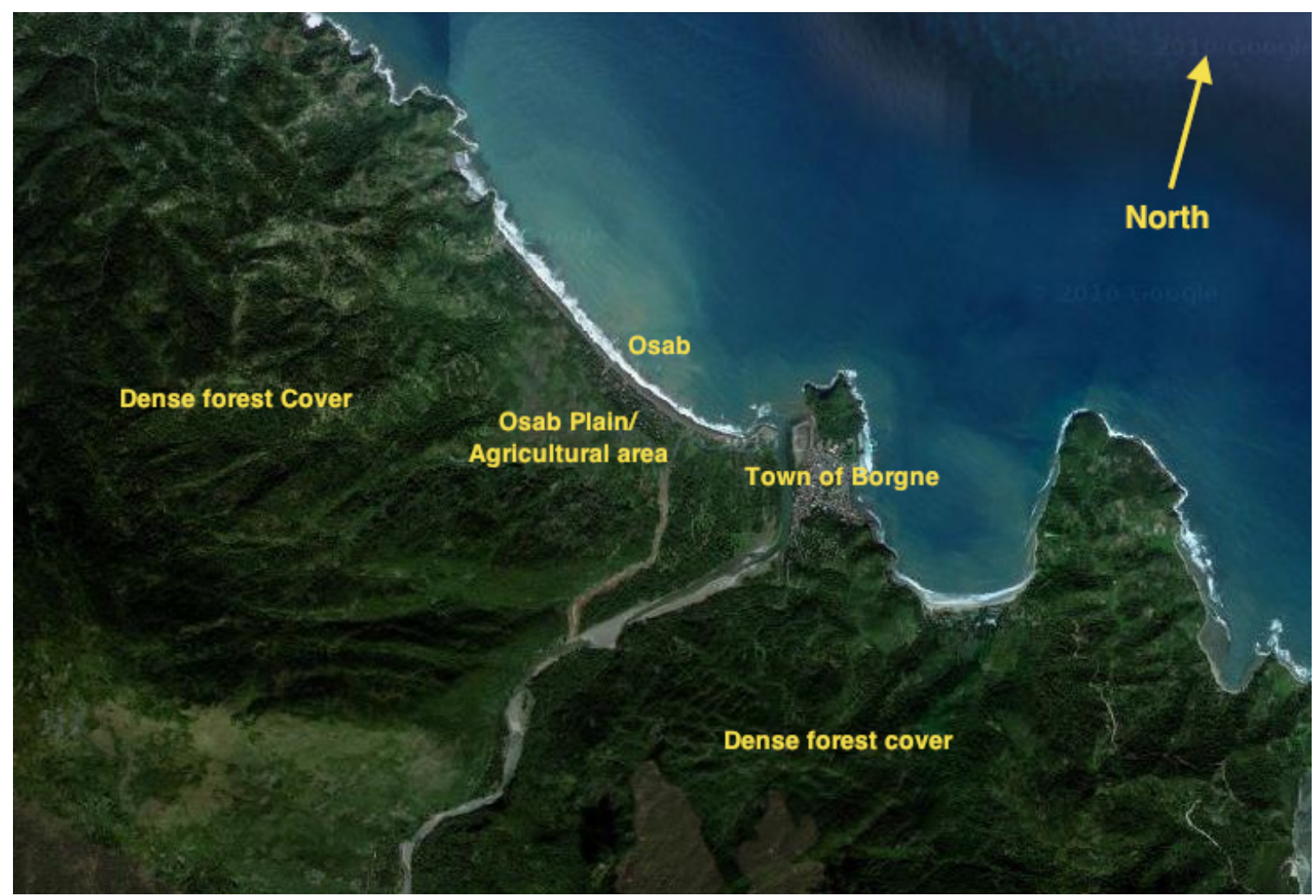

Image Courtesy of maps.google.com

Osab is also particularly relevant as it is home to both the primary tree nursery, most of the tree planting project's employees and a significant number of participants. Though trees were distributed throughout the countryside surrounding Borgne, the majority my research was completed in the communities surrounding Osab because of its proximity to Borgne and the relationship that I developed with key informants in the community. Many residents of Borgne also own or work land across the river in Osab, marking it as an important example of the values practiced by the community. 


\section{IIb. Trees are the Difference}

Moving beyond basic descriptions, the most relevant and indeed most remarkable aspect of the geography of Borgne is the significant number of trees that dominate the landscape, especially when compared to the rest of Haiti. Though the often cited statistic that only two percent of Haiti's remains tree-covered is always relevant, the physical presence of entire tree-covered mountains cannot be overstated as a factor that shapes the community of Borgne (Homer-Dixon 1994: 34).

When travelling on the road west out of Cap-Haïtien towards Borgne, after about twenty miles the denuded landscape that dominates most of the Haitian countryside is slowly replaced by a marked increase in vegetative presence on the distant mountains. Entire ravines and mountaintops are green with trees and nonagricultural flora.

Continuing another few miles down the road just outside of Borgne the definitive transition continues; enormous rolling mountains run parallel to the roadway and dominate the landscape. Their tree-cover has been almost entirely preserved and were it not for knowledge of geography they might have been cut out of the American Smoky mountains and pasted along the coastal route. This pattern of arboreal preservation only continues and expands upon entrance into Borgne proper, where the surrounding mountaintops are almost always cloud-covered.

As the title to this chapter suggests, Borgne has defied the dominant narrative of deforestation in Haiti. Indeed the Borgne of today that appears as a lush vegetative climate is much more indicative of the entire island that Columbus discovered in 
1492 (Lundahl 1992: 27). Several historical and economic factors that have led to Haiti's current environmentally denuded state. Historically, deforestation began as a colonial endeavor to clear land for plantations however the process continued after the revolution when "new governments let out extensive logging contracts to international firms in order to gain hard currency" (White and Jickling 1995: 5). Though not worth recounting at length for the purposes of my research, Haitian economic development guru Mats Lundahl, who has written prolifically on Haiti, isolates three primary factors that have more recently contributed to Haiti deforestation. Lundahl cites limited access to land and capital for agricultural production, lack of access to non-agricultural employment and finally severe economic and social insecurity. White and Jickling (1995) add that these "proximate causes are products of population growth, and, more importantly, of a history of governments that have maintained policies biased against peasant producers" (White and Jickling 1995: 2). Thus while historic factors have contributed to Haiti's deforestation, the most prevalent and currently relevant factors have emerged in recent decades.

\section{IIc. The Road: Beauty and Curse}

Also to be taken from the approximately thirty-mile ride from Cap-Haïtien is the relative isolation of the community of Borgne. Because of the poor quality of the unpaved road, the entire ride from Cap-Haitien to Borgne on a good day with no rain and relatively few unaccountable delays takes between two and a half to three hours. Given that this journey is typically experienced packed onto the back of a flatbed truck or loaded into a small bus or van, I was actually rather relieved when we got a 
flat tire and had to pause by the side of the road to stretch. While travel is difficult for passengers, charcoal, which is most of the nation's primary energy source, must make the same journey, packed onto the same type of vehicle over the same difficult roads. Such difficult transportation has had serious impacts on the community of Borgne, simultaneously producing both negative and positive effects on the culture and economic prospects of the community.

The phenomenon of isolation has left many of Borgne's trees protected from the national energy market that has destroyed much of the rest of Haiti's trees, which are cut and used primarily to produce charcoal for market or as construction materials. This isolation by transportation is not new however; prior to 1950 "there was no direct road link with the outside. All contact with administrative centers such as Cap-Haïtien was by foot, animal transport, or the sea" (Maguire 1981: 24). Thus it is evident that while most other parts of Haiti have been internalized into the national energy market, Borgne's delayed inclusion has allowed it to keep a valuable natural resource in its trees. In this way, Borgne is the exception to the general rule of severe deforestation that plagues most of the rest of Haiti.

The negative side of this duality however, is that a lack of access to outside economic markets via road diminishes the amount of goods that can be sent to larger national or international markets such as Cap-Haïtien or destinations abroad.

This duality in so many ways describes the fate of Haiti, exposed to the turmoil of harsh international market forces but impotent to be able to fully participate in that same market that punishes it. The economic case of Borgne is a 
microcosm of this, with a lack of national market exposure preserving natural resources while simultaneously disallowing full participation in that market that has the potential to lift the community out of grinding poverty.

A deep understanding the dual role that the road offers does not escape Borgne's community leaders. Historically, peasant efforts to improve the road out of Borgne so that they might export their rich coffee crops to the large markets in Limbe and Cap-Haïtien have met harsh resistance from powerful and politically aligned coffee speculators. Several massacres of peasants took place in the years following the fall of Duvalier (1987-88), after peasants demonstrated to ask that the national government fix the price of coffee at 5 goud per pound (at the time US \$1). Longtime political activist Marc Lamour, who has been active in organizing the peasantry around Borgne since 1983 and was the official "peasant delegate" of the Aristide administration in the early 1990s, explained the role of the road as a duality in a brief conversation with me over a bucket of mangos (Arther and Dash 1999: 93-94). Holding up a smaller variety of mango he said: “These mangos are the best. They're as good as any other country in the Caribbean, but we have no way to get them out." As we continued to talk, he simply nodded solemnly when I confirmed my assumption that improving the road might mean the loss of many of Borgne's trees. However, it would seem there is no other way forward if the agricultural producers of Borgne want to expand into larger markets. While the long-term implications of the conditions of Borgne's road are yet to be measured, they may soon come to a head. At the conclusion of my study period, as I rode the small bus out of Borgne back towards Cap-Haïtien, earthmovers and other large machines briefly delayed our 
journey. While I was initially puzzled by their presence, it turns out that in the six weeks while I was completing my research, contractors had paved significant portions of concrete roadway. Borgne's relative isolation may soon come to an end.

\section{IId. Pye Bwa yo se Lavi - Trees are Life}

While the economics of this isolation might be discussed at great length, a more important human element must be considered. Though this will be discussed further in the following chapter, the presence of dynamic community organizations in Borgne has been an important factor in producing and preserving a unique cultural of environmentalism.

Because of the previously described phenomenon of delayed inclusion into national markets, the community of Borgne has developed a general culture that values its trees, and understands them to be a natural resource of intense valueespecially compared to the rest of Haiti (there are exceptions to this however). While time and underexposure are certainly factors in this phenomenon, the community organizations have also played a significant role in fostering this culture. Erik, the primary architect of the tree project, described this to me as we sat in his small shop:

Look around us. Everything is wood. We're sitting on wood. You're writing on wood product. Education and intelligence, gets into our head because of the paper that comes from trees. We can't do anything without wood and we know it's an important part of our life here. We die, they bury us in a wooden box.

Bearing this in mind, these small, grassroots organizations have systematically 
embraced this isolation through the use of several tools that not only seek to preserve trees but celebrate the culture the emanates forth from the fact that those trees remain. Summarizing this, one agent from MODEIB explained the difference, noting that "It's simple, the difference here is that we understand the value of trees. Here, everyone knows that trees are life." This is phrase of "trees are life" is common in conversation with Borgne's residents. It also is not age, gender, income, or educationally bias as the almost anyone will describe their community as "the most beautiful in Haiti, for we have trees.”

While the general attitude of valuing trees pervades throughout Borgne, this is not to paint a utopia by where trees are never cut. Curious about this, I was led by my informant Daisy to a piece of land she owned way up on the steep mountainside about an hour outside of Osab. Daisy, who in many ways exemplifies the environmental efforts of the community, described to me all of the trees she planted upon her return to Osab in the 1980s after having spent 15 years in the Bahamas: "When I get back from the Bahamas, I started planting trees here and I figure I'm just gonna leave it. Not touch it. Just for no other reason than that the birds can have a home." As we walked up to her largest tree, she pointed out that someone had cut all of the bark off around the base: "They're killing it, getting ready to cut it down and steal it."

I happened upon a similar situation while visiting the land of Juanito, who was taking me to show me his personally grown and project provided trees. Juanito has been planting trees for many years in Borgne and besides being an active project participant, he also had his own backyard nursery. Upon arriving to his mountain plot, we found that it had been entirely cleared of brush and a few of the older trees 
he planted were cut down. Given the large black pits, he suspected charcoal thieves. Given these two scenarios, it is clear that while most individuals are active in preserving and planting trees, notable exceptions do exist. Unfortunately, with road improvements, this may become a more frequent occurrence.

Apparently aware of these challenges, the community organizations often discuss the idea of "defending the section." Though they are referring to the political unit ("section" or seksyon is a geographic demarcation) and are not necessarily discussing taking up arms in defense of their community, their language is indicative of a high level culture of protecting what they perceive to be subject to the pressure of a litany of external forces.

This fervor in many ways is of little surprise given Borgne's location, especially when juxtaposed against the canvas of history. It is said that every revolution or revolutionary movement starts in the North of Haiti. Borgne typifies this as a hot bed of both historic and more recent resistance. Historically, the area near Borgne is the locale of guerilla revolutionary Mackandal, who led the first of the resistance movements that eventually led to the overthrowing of the French during the Haitian revolution. More recently Borgne's resistant spirit was evident through the position of resistance the community organizations took in response to the 1991 coup d'état of Popular President Jean-Bertrand Aristide. The leaders of several of the organizations that I surveyed in my research took up arms took to the mountains or went into hiding — in some cases for years on end — so that their cause might be served. It is this same culture of resistance and "struggling for the section" that exemplifies the "culture of environmentalism" that was previously mentioned. 
Considering these factors in total and combining the significant number of trees still remaining in Borgne with dynamic and active community organizations that have for decades been rooted in a distinct culture of resistance, has produced a unique culture of environmentalism. Another more tangible product of this culture product is the current tree planting project, the implications and descriptions of which will be a significant portion of this study. A final factor to be considered is the presence of the Agroforestry Outreach Project in the community during the late 1980s. Though the other factors played an arguably more significant role in terms of the culture that has developed in Borgne, the AOP presence provided the skills necessary for the current tree-planting initiative and cannot merely be considered as a tangential factor. I will discuss the role of the AOP more in the following chapters of this study, along with a more full description of the tree-planting project and its historic origins.

\section{IIe. Methodology and Bias}

The factors at play in Borgne that I previously discussed combined with my own specific views called for a blend of research techniques to be employed in completing field work. In an effort to build rapport and inform the community organizations working in Borgne of the nature of the intended research project to be completed, I sought to begin this process by introducing myself to any local community leaders that could be reached. I attended any meeting that I could, announcing the intentions for my research and making contacts that I could join in the field. The principal method that guided this process was the "snowball method" by where one contact is made through other contacts (Bernard 1998: 703). Though it was not my dominant research method, this was an important jumping off point and 
allowed for the employment of the other major research techniques used in the actual collection of data: Participatory Action Research (PAR) and semi-structured interviewing.

Though Participatory Action Research is part of a much larger theoretical sphere, for the purposes of my research it can be defined as a method of study by which the researcher actively engages in the efforts of the community or organization under study. The researcher takes a hands-on role and completes work directly on the behalf of those under study. This can involve a broad range of activities but it typically involves those under studying guiding the researcher in designing and completing his research (adapted from Whyte 1991: 20). In my specific case, I adapted the principles of PAR to make myself fully available in any capacity to aid the efforts of the community organizations being studied (MODEIB, OGPK, as well as the additional gwoupman which will be discussed in the following chapter). "Fully available" in this case involved a wide range of activities, all of which centered on trying to understand and ultimately aid in the long-term efforts of both individuals and community organizations as a whole (as is part of the overall goal of my research).

This process began with a key informant, Daisy, a 70-year old woman who is a respected elder in Borgne and Osab. Because Daisy and I spent a significant amount of time together during my previous trip to Haiti in January of 2010 and experienced the earthquake together, achieving the bond necessary for research was not difficult. During the first few weeks I spent almost every day with Daisy. She introduced me to key community members and we spent hours in her fields, watering, 
weeding, planting and harvesting. While she taught me the ways of rural Haitian agriculture, she perhaps more importantly saw me not as a blan but as a capable young man who could learn to handle a machete as well as any Haitian. Though I did my best to defy her by slicing my thumb open one day while weeding, she ultimately gave me the confidence I needed to complete agricultural labor with the community organizations under study (who were, to say the least, skeptical of my skill set).

Having been put in touch with key organizational leaders, I engaged in manual labor on collective agricultural workdays and attended the meetings of various organizations. Further, I helped Daisy (who is employed by the tree project) tend to the organizations tree nurseries and visited newly distributed tree seedlings with another community leader employed by the project.

Despite the constrained period of time for this study (only six weeks were spent in the field), I was able to isolate several important factors surrounding the organizations using PAR and semi-structured. While I explored the history of the organizations, I tried to place greater emphasis on the method by which community members mobilized to diagnose a communal problem and collectively work for solutions. Combining these interviews with PAR, I completed corresponding followup visits and workdays with various interviewees and organizations. The wedding of these two methods allowed for a natural relationship to develop between talking to subjects and then participating in their efforts.

The use of PAR also allowed me to identify the technical agronomic methods that the organizations use to prevent environmental damage within the commune. These include but are not limited to the construction of community nurseries that 
provide tree seedlings to community plot holders, the systematic monitoring of those trees provided by the organizations and the specific agroforestry methods employed to prevent further damage to land.

Finally, I want to acknowledge the bias present within this thesis. Though in some ways an offshoot of PAR, my research is driven both in methodology and overall intent to shed light on the grassroots organizations of rural Haiti. It is my belief that the work of the organizations profiled in this thesis represent is an integral but underrepresented part of the Haitian development process. Thus, it should be understood that while the overall academic objectiveness of this thesis has not been compromised, my own views have significantly shaped its design and methodology. 


\section{Chapter III: Heads Together: Civil Society in Obòy}

\section{IIIa. A Rural Majority}

Following a thirteen-year struggle that saw the involvement of almost every major European power, the former slaves of the French colony of Saint-Domingue established Haiti as the world's first black republic in 1804. Though the plantation system dominated the colonial area, with independence former slaves divided up the large estates of their ousted colonial masters into the smallholdings that have become to characterize life among Haiti's rural population. Despite initially being confined to the country's large coastal plains, the growth of the population and the corresponding demand for land, mandated that cultivators move further and further into the mountainous hinterland (Arthur and Dash 1999: 80). This expansion into the mountains led to previously discussed environmental issues (deforestation and erosion) but it has also had a severe social impact.

Throughout Haiti's history, a rural-urban class divide has dominated society, with the rural majority largely excluded from the gross concentration of wealth among a small elite in the capital. This tiny urban majority has centralized power and decision-making, which is reflected through government programs that cater almost exclusively to the urban population (Maguire 1981: 12). In response to this, rural peasant society has "emerged as largely self-regulating to cope with geographic isolation, exclusion from the political system, exploitative market relations, regressive taxes, and the virtual absence of state investment in the rural sector. [Further, they have] created a complex network of local institutions to ensure social security and channel access to land, labor, and capital" (Smucker, White, and Bannister 2002: 3). 
Thus, while "it is not uncommon for analysts to claim that [Haiti] has no real civil society," there in fact exists a rich and diverse social infrastructure that governs the rural areas (Smith 2001: 3).

One important expression of this social infrastructure, civic organizations or "peasant groups" are diverse in nature and can range from temporary agricultural labor parties konbit (a Kreyòl word for collective farm work on individually owned plots) to squads (eskwad) that work together for monetary compensation. They also include more advanced, highly formulated groups known as sosyete that beyond "serving as an organized medium for collective agricultural labor, also may serve as informal law-enforcing and judiciary bodies" (Vannier 2010: 287). The spirit of cooperation and collective action from where these organizations (many of which have been present for centuries in rural Haiti) have emerged "reflects a larger commitment to sharing labor and resources that goes well beyond pragmatic interests, and comprises one of the very foundations of rural Haitian culture" (Smith 2001: 72).

\section{IIIb. Gwoupman Origins}

The nature of rural Haiti's communal spirit has also lent itself to the efforts of outside entities that have sought to transform it into a tool by which aid could be delivered and development projects could be completed. This transformation began in the early 1960s with the introduction of "community councils" as part of the Central Government's Code Rural - an effort to incorporate the rural citizenry into the larger national fold. Unsurprisingly, the groups were largely ineffective and were used mostly as a tool for control and surveillance; to quell the incessant fear of the 
Dictator Duvalier that rebels were hiding in the countryside plotting revolution (Smith 2001: 148; Vannier 2010: 288).

Though they did little to change the impoverished communities of rural Haiti, the community councils did lay a foundation that illustrated the potential for smallscale collective action for the sake of development. A corresponding shift in foreignassistance efforts moved away from providing materials and instead focused on "bottom-up" techniques that emphasized a people-centered approach. These techniques were proliferated by NGOs but also by the Catholic Church, who escalated their efforts following the 1968 Vatican Conference of Bishops in Medellin. This conference, which was famous for the Liberation Theology movement that followed, saw activist priests pledge to the aid the poor in the struggle for the social and economic justice (Vannier 2010: 288).

The tangible reflection of this was seen in Haiti with the opening of Churchsponsored training centers that taught young Haitian leaders from rural communities the skills behind grassroots organizing. These individuals were trained as "animators" (animatè) to "motivate residents of a locale to organize into small community groups; [to] guide these groups in a process of reflecting together on social problems; and teach group members how to work together effectively for positive social, economic, or political change" (Smith 2001: 151).

This "groupement" (from where gwoupman is derived) process had a dynamic effect on the civil society and with the 1981 change to the U.S. Government's Foreign Assistance Act, which required a grassroots approach that bypassed the corrupt 
Haitian government, USAID Haiti began sponsoring "groupement" projects. Prolific Anthropologist Glenn Smucker and his team completed one of the early analyses of a USAID-Haiti rural development projects that revolved around the formation of "groupement." The project describes the role and function of gwoupman: "These small groups constitute the building blocks of inter-group activities leading to cooperative formation. The goal of this project is to help the rural peasantry organize small self-assistance groups and work collaboratively to generate savings and undertake small-scale commercial and production activities" (Locher, Smucker and Woodson 1983: 2). An additional definition allows for a more basic understanding: “gwoupman peyizan (literally, 'peasant grouping') is a label used for a wide variety of local organizations, most of which aim to bring about social, economic, or political change" (Smith 2001: 141). Though Locher et al's definition provides an excellent foundational explanation for gwoupman, the second definition from anthropologist Jennie Smith offers a broader definition that allows an understanding that incorporates the way in which the gwoupman phenomenon has evolved in recent decades.

The gwoupman of today reflect a diverse history that has seen an ebb and flow of membership due largely to the somewhat volatile nature of Haiti's political climate. This pattern began with the distinct role that rural organizations played in the ouster of Duvalier in 1986. The dechoukaj (uprooting) of Duvalier went hand-inhand with Church's role in organizing rural communities through animatè programs and training centers. In the wake of the euphoria that swept the countryside, rural organizations rallied behind liberation theology priest Jean-Bertrand Aristide, who 
was eventually elected in 1991 as the nation's first democratic president (Vannier 2010: 290). The tumultuous set of coups and controversy that have surrounded Aristide have had a significant impact on rural organizations, many of whom have faced violent repression from opposition groups. Despite these challenges, rural peasant organizations continue their work and continue as a key part of Haiti's rural civil society

\section{IIIc. Tout Moun Konprann Gwoupman! Everyone Understands Gwoupman!}

Borgne has been no exception to the rise of the gwoupman phenomenon and this model represents the primary building block for civil society in Borgne. Borgne's gwoupman complete a wide range of development-oriented tasks and many belong to larger overarching organizations through which funding, both governmental and non-governmental, is distributed. Borgne's gwoupman and gwoupman-based community organizations are also diverse in age with some organizations boasting 20 plus years of activity and others forming within the past few months.

Gwoupman in Borgne can be defined as: groups of 5-20 people, both men and women, that typically align themselves based on kinship and geographic proximity for the sake of community improvement through collective action. This can involve engagement in shared agricultural activities, infrastructure development, pooling of economic resources or even political alignment.

Moving beyond the neighborhood level, many gwoupman have organized into regional organizations that work on a larger scale, both geographically and in the depth of the projects in which they engage. In the case of Borgne, following the 
introduction of gwoupman kominotè a (community level gwoupman), a Haitian priest helped organize many community gwoupman into a larger civil structure. The history of these regional "second-level" organizations of gwoupman varies however, though most were aided or organized with some degree of help from the Catholic Church. This help was in some cases directly completed by priests and in other cases was the indirect work of the aforementioned animatè, who were trained at Church sponsored training centers (this is documented at length in Robert Maguire's Bottom-Up Development in Haiti (1981) which cites Borgne as a specific example).

The introduction of the gwoupman model, despite its ebb and flow in membership has endured since its introduction and is continuing to evolve in Borgne. During my research period, a new gwoupman formed in Borgne in the community of $\mathrm{Sab}$ and an additional large community organization with representatives from several areas of the greater Borgne seksyon also had their first meeting. Though there are notable exceptions, seemingly every neighborhood or small geographic area outside of the town-proper had its respective neighborhood gwoupman that completed various collective agricultural and community tasks on the respective plots of the membership. In some cases individual leaders involved with gwoupman completed several roles in varying organizations at, for example, a neighborhood and then section-wide level, often representing their neighborhood gwoupman in the larger community organizations. While, as one gwoupman leader proclaimed Tout moun Konprann Gwoupman! (“Everyone Understands Gwoupman”), the way in which these organizations interact produces a layered and complex civil society that merits further explanation. 


\section{IIId. Community Organizations in Obòy}

In the sections that follow, the various gwoupman and organizations in Borgne will be reviewed and explained, along with the types of work that they complete and the way that they interact. For analytical purposes, the first two organizations I profile can be described as "newly formed gwoupman" while the final one can be seen as a second level organization that is more complex in nature and has been existence for a longer period of time.

\section{Gwoup Agrikòl Tèt Ansanm Petit-Guinèe}

The Gwoup Agrikòl Tèt Ansanm Petit-Guinèe (the Heads-Together Agricultural Group of Petit- Guinèe or GATP) is a gwoupman based just outside of Borgne proper in a small area known as "Petit-Guinèe." Founded December 17, 2008 with 15 members, the mission and reason for creation was to bring a cooperative spirit into tangible existence and to work toward reducing poverty in the Petit-Guinèe community. Skill sharing, teaching and charity are a major part of the GATP ethos. Outside of working their own individual plots as a collective (as is typical of gwoupman), the organization also rents a communal plot of land. Though they sell what they can (there is a lack of available markets), they often fè kado (literally "make gifts") of the food they grow, providing to poorest community members in Petit-Guinèe

The group also frequently works on the plots of those community residents not yet part of the GATP. This is done as an effort to illustrate the benefits of working in a group so that the GATP membership will expand to include more 
residents. Beyond the collective agricultural work, GATP is engaged in an animal husbandry project that has purchased goats (though when they have enough money they hope to expand to cows). They also are engaged in water redirection efforts to aid with both erosion and to collect water for irrigation. GATP is a registered member of the Konfederasyon Gwoupman Peyizan Bòy (The Confederation of Peasant Gwoupman Borgne or KGPB), which is a section-wide overarching organization that coordinates and distributes funding to the zone's gwoupman (Note: I was unable to interview the head of KGPB as he was called to the capital during our scheduled interview and thus I do not have a deep enough understanding of KGPBs role to profile them at length in this thesis).

\section{Linyon}

The gwoupman Linyon (Union) was the youngest organization in the area, founded in the month before this research was completed in June-July of 2010. Geographically based in Sab, the founders are also participants in other organizations as well as volunteers in the Technology Center run by one of the NGOs that operates in Borgne. The organization was founded out of necessity and an expression of Sab residents to work together on a more regular basis. Membership was relatively high with at least 34 community members involved. Because of the brand new nature of this organization, they had not completed many projects beyond a few konbits (agricultural work parties). Though they were not yet registered with KGPB (and thus not yet eligible for funding), they were in the planning stages of their projects and were already collecting money. They also took over the management of the local water pump, which was a relatively new installation in the community. More than 
anything else, Linyon serves as testament to the fact that the gwoupman model is still growing and evolving within the community.

One contributing factor that runs through these two newly formed gwoupman is leadership. The individual leaders of these organizations are both highly involved community members who are engaged in multiple organizations aimed at improving their community. They have importantly gained the experience and trust of those they serve. As I observed their actions in meetings and discussed various issues with them, I began to see them as the types of individuals who would under different circumstances be engaged in the community through local governmental leadership. They appeared, even in their frustration with their own situation, as the civic leadership that one might see in an American City Council or neighborhood organizational meeting.

\section{Òganizasyon Gwoupman Peyizan Kote-de-Fer}

The Òganizasyon Gwoupman Peyizan Kote-de-Fer (the Gwoupman Peasant Organization of Kot-de-Fer or OGPK) is one of the larger inter-community or regional organizations that is made up of several gwoupman from the town and countryside around Borgne. Founded March 29, 1989, it is one of the older organizations in the community and was born out of post-Duvalier euphoria. Under the leadership of a Haitian Priest named Pierre Pikyon, OGPK was formed so that all of the "gwoupman kominote a" (community gwoupman) could "put their heads together and work for development."

OGPK currently has sixteen gwoupman in its membership from different 
localities around Borgne. Each gwoupman sends a representative to meetings and collective agricultural work parties, which are completed on the plots of various members. Additionally, OGPK has sends five members as representatives to Borgne's largest overarching organization, Konfederasyon Gwoupman Peyizan Bòy (The Confederation of Peasant Gwoupman Borgne or KGPB). Beyond working on member plot, OGPK has also completed a number of larger projects. These include the construction of a passable mountain road connecting Borgne, Sab and ChapelDumas, a latrine building project, an adult reading program, a chicken breeding project and of course the various agricultural projects routine to rural Haitian communities (clearing land of brush, weeding, planting, harvesting, etc.). Additionally, OGPK has been very involved with the current tree-planting project. Their role in the project will be discussed further in the following chapter.

\section{IIIe. NGO Presence}

Outside of the numerous Haitian community organizations, there are two foreign Non-Governmental Organizations that currently operate in Borgne and the surrounding countryside. Haiti Outreach Pwoje Espwa (HOPE) has been working in Borgne since 1995. HOPE has run a variety of projects over the years but they are currently engaged in education initiatives, water and sanitation projects, and they provide the community's only medical services through a large clinic. Most germane to this study is that HOPE funds the tree-planting project, which has been operating now since 2007. Additionally, HOPE provides funding to various gwoupman through their work with KGPB. This represents a very interesting "grassroots" model that contributes to the civil society already in place and stands in contrast to some 
other organizations that import robust foreign structures or contribute to an internal "brain drain." This "grassroots" model is also interesting when compared to the other organization operating in Borgne, who operates with a similar "grassroots" mindset.

The second NGO operating in Borgne is Sustainable Organic Integrated Livelihoods (SOIL) and their Haitian sister organization Sosyete Òganize pou Lanati (SOL). Based in nearby Cap-Haitian, SOIL/SOL have worked in Borgne since 2006 and are deeply connected to Borgne through one of SOIL's co-founders-who lived and worked in Borgne prior to co-founding SOIL.

The primary mission of SOIL has been to introduce public sanitation infrastructure through ecological dry toilets that prepare the waste for composting. From a public health perspective, the toilets handle and treat sewage so that it does not infect the public water supply. After the toilet is full, the human waste (which is mixed with sugar cane bagesse or similar dry material) is then taken out to a composting site where it is turned into nutrient rich compost. This compost is especially valuable in Haiti because of the largely agricultural economy and the poor soil quality that is prevalent throughout the country. Thus, SOIL is tackling several key "Haitian" development issues at once: they are providing public health and sanitation through their toilets, and nutrient rich compost to bolster the severely depleted Haitian agricultural sector-upon which most of the population relies for their livelihood.

In regards to reflecting a "grassroots" model, SOL, SOIL's sister organization, provides the native insight that a foreign body could never hope to achieve. 
Additionally, SOIL supports three technology centers around northern Haiti, one of which is in Borgne. These centers serve as jumping off points for the monitoring and maintenance of rural toilets, which is completed by a locally employed Haitian team on a monthly basis. Water quality is also tested and toilet requests, which frequently come from local community leaders, are handled and processed. In terms of raw infrastructure, SOIL/SOL has constructed 11 toilets in Borgne and, at the time this research was completed, had 30 letters requesting toilets from communities around Borgne.

Several volunteers and employees of both SOIL's Technology Center in Borgne, and the HOPE clinic are also heavily involved with other civil organizations throughout Borgne. This overlap seems promising in terms of the impact that the NGOs are having on the community, working within and with leaders of civil society rather than bypassing them by importing foreign structures to complete development work. These activities of these organizations, particularly the tree-planting project that is funded by HOPE, build upon a greater legacy of NGO presence in Borgne. Though various other international organizations have historically worked in Borgne, perhaps the greatest contribution to changing the cultural and environmental fabric has been the presence of the Pan-American Development Foundation/USAID Agroforestry Outreach Project.

\section{IIIf. The Agroforestry Outreach Project}

As was mentioned in Chapter 1, the largest tree planting initiative in Haiti was the Agroforestry Outreach Project (AOP), a joint effort with the United States Agency for International Development (USAID) and the Pan-American Development 
Foundation (PADF) that ran under various auspices from 1981 until 2000. The AOP worked extensively throughout rural Haiti and at its zenith had 36 nurseries that produced approximately 10 million trees annually. The nurseries were professionally run by smaller, contracted NGOs that after growing the trees would sell them to PADF — who would organize the seedlings and distribute them on the local level. Local residents were trained as extension agents and would put in orders based on the species and quantities requested by the community they represented (Murray and Bannister 2004: 386). In total the project distributed millions of seedlings to over 300,000 families throughout rural Haiti (383). Though the success of the project on a physical level is contested (Haiti is still largely devoid of trees), the cultural impact may have been more profound.

The AOP in Borgne

The PADF and the AOP began distributing trees in Borgne in 1988 and continued through the early 1990s. The trees were distributed by truck during the rainy seasons in May and October, from a nursery in nearby Cap-Haïtien, about 25 miles east of Borgne. The distribution of trees was completed by a group of PADFtrained and employed informateurs, who educated and prepared the local community for the distribution of trees and facilitated the desired quantity and species of trees (both hardwoods and fruit trees were provided). Many of these trees still dot the landscape and are in remarkably good health—-the large hardwoods untouched and the fruit trees still producing. Several members of community organizations mentioned PADF trees as a part of the explanation for the green landscape 
immediately surrounding Borgne. They believed most trees were wild but mentioned that those which are not are likely PADF tree or trees from the current project.

This physical presence of trees however, is indicative of the AOP's larger impact on the community of Borgne. A few of Borgne's key community leaders, as well as the manager of the current tree-planting project, were part of the PADF extensionists team that prepared the community to receive PADF project trees in the late 80 s and early 90 s. These individuals, who now occupy leadership positions within the community, were trained extensively in the practices, value, distribution, education, and care of tree production and distribution. Combining these skills and a profound understanding of the value of trees with the dynamic community organizations of Borgne has without a doubt had a significant impact on the culture of environmentalism that is ubiquitous in Borgne. In this way, perhaps the importance of the AOP has not been in the physical trees they provided but rather with the skills, values and understanding that they left in the community. In the following chapter I will explore the tangible implications of those skills, which combined with other factors, manifest themselves currently in the form of a community wide tree-planting initiative. 


\section{Chapter IV- Defending the Section: Local Initiatives in Action}

Bwa gen zòrèy, sak ladan'l se moun. - The woods have ears. What's in them are people. - Kreyòl Proverb

\section{IVa. Wordplay: Defending the Section}

With its colorful linguistic tricks and dynamic proverbs, Haitian Kreyòl provides powerful insight into the mentality of its speakers. Perhaps no phrase illustrates this point more than the one commonly cited at the meetings of the various community organizations in Borgne. In reference to the section, a geographic unit denoting Borgne and the surrounding areas, many members use the phrase Nou ka defan seksyon an (We can defend the section). The strong imagery evoked by this expression references a spirit of civic values and a willingness to struggle for the community in which one lives (beyond imagery, it is worth noting that several organizations in Borgne did resist the 1991 coup against then popular President JeanBertrand Aristide; see Shacochis 1999).

In the case of Borgne, this spirit is paralleled to the community's ability to protect their natural resources, particularly their trees. As previously mentioned, due to their relative isolation from the larger markets of Haiti, Borgne has managed to keep a large number of its trees out of the reach of the nation's voracious charcoal market — which, combined with other historical factors, has decimated much of the rest of the islands environment (Homer-Dixon 1994: 34). Combing this isolation with the previously described influence of the AOP and dynamic organizations that are engaged in community improvement efforts, has produced the aforementioned 
"culture of environmentalism" by where an extreme value is placed upon the presence of trees in the community.

Given the high value of the trees that cover the mountains around Borgne, it is of little surprise that the actions taken to "defend" the section have principally manifested themselves in the form of tree-planting project that increases the natural assets of Borgne's plot holders by thousands of trees per year. The details of these efforts, both in tangible practice and cultural implication, will be addressed below.

\section{IVb. Foundations}

Despite the complex nature of what the it represents, the origins of the current tree planting project, like the project itself, are simple enough. In 2006, upon observing the disappearance of trees along the coastal mountains - and the subsequent erosion that followed, two of the community organizations in Borgne and neighboring Kot-de-Fer, began to search for solutions. The organizations, the Movement for the Integral Development of Borgne (MODIEB) and the Gwoupman Peasant Organization of Kot-de-Fer (OGPK), noted the particular ecological value of trees along the coastal mountains, which are exposed to the harsh Atlantic winds. Because of the importance of the health of the environment as related to local agricultural systems and the local economy, the organizations recognized the importance of preserving the remaining environmental resources. The organizations also recognized the economic value of trees in and of themselves, and wanted to replace those that had been lost. "Trees are life" also means, as one community leader noted, "that everything around us is wood, and the community will almost always need wood." 
After "putting their heads together", the two organizations created and submitted a proposal to the American NGO Haiti Outreach Pwoje Espwa (HOPE). The proposal sought funding to begin a program that would provide trees to local residents of Borgne. In 2006, HOPE provided its first round of funding and the project was launched, with the first trees delivered in that same year. Though it has not received funding every year, the project most recently ran during the period of my research, in the summer of 2010.

\section{IVc. Nurseries - Pepinyè yo}

The foundational piece of the project is its two nurseries, each of which is capable of producing up to 35,000 trees per year (though in reality they produce much less due to budgetary constraints). The construction of the nurseries is simple and rustic — but functional. Lacking the plastic sheeting of a professional nursery, a wooden poll frame covered on top by palm fronds houses the growing seedlings. The palm fronds serve the same function that plastic might, protecting the seedlings from both rain and excessive sunlight, and are easily adjusted or removed if necessary.

The seedlings themselves are grown in small (about $3 \times 5$ inches), clear plastic bags in which drinking water is sold. Often discarded in the street by their consumer, the plastic bags are collected by the project (or sometimes by local children, who are given a small amount of money for their efforts) and prepared for their new role handling young seedlings. This preparation process involves cutting one end of the bag open completely and clipping a series of small holes in the opposite end to allow for drainage. The bags are then filled with soil and placed side by side under the shelter to allow for easy watering. The project has experimented with dung compost 
but it has gotten too hot and burns the young plants. An alternative type of compost that uses dry leaves is also being worked on by the project but has yet to be implemented fully.

By nature of their rustic design and relatively low production, these nurseries stand in opposition to the logic of "economies of scale" which is described by Murray and Bannister as one of the reasons for favoring professionally nurseries over so called "backyard nurseries" (Murray and Bannister 2004: 385). However, despite the relatively small number of trees compared to the large professionally run nurseries of the AOP, every aspect is found locally — from the palm fronds to the discarded plastic bags. On a functional level, this keeps costs down since unlike the AOP their external funding is extremely modest, while still providing an important environmental service, in the form of valuable trees, to the community. It also represents a local model that is flexible and adjustable to circumstances immediately present within the community.

Additionally, the project employs local individuals who oversee and manage the nurseries. These individuals, who are referred to as pipinyèris in Kreyòl, serve as nursery managers and are involved with every step of the tree-planting process. There are three pipinyèris for each of the two nurseries. After the tedious job of preparing and planting the trees in the thousands of small water bags (which must also be prepared for their new role as pots), the job of the pipinyèris is to take care of the trees through the process of maturation before trees are ready to be distributed by the project. Trees are watered, checked for health and the nursery is kept in order. Each pipinyèris has been trained in these techniques by an agronomist, who is 
brought in to train all employees of the project. Outside of receiving cash payments for their employment, food is also prepared and given to those employed by the project.

\section{IVd. Diverse Species, Diverse Benefits}

The species of trees employed by the project are a mix of tropical hardwoods and fruit-bearing trees. While the presence of trees in and of themselves provides a profound ecological benefit (Borgne's residents often attribute their almost daily rain with the presence of large numbers of trees), the species used in the project are also selected for the economic benefit that they provide the community. Fruit-bearing species can provide their owner either healthy sustenance when consumed at home or might also garner cash from sale in the local market. Further, seeds produced from fruit trees are often replanted by their owner, which ensures future benefits for the owner or his progeny. Non-fruit bearing hardwoods are also employed by the project. These species also provide a balance of ecological (enriching the soil, holding water, etc.) and longer-term economic benefits to their owners, the latter of which comes in the form of construction materials that can be used by the owner or sold to an interested buyer. The wood species selected by the project are characterized by their fast-growth but notably provide a greater benefit in the form of construction materials than charcoal. Though the project cannot guarantee that they will not become charcoal, by selecting fruit-bearing trees and trees that fè bel planch ("make good planks"), the incentive is provided for the owner to couple longer term economic benefits with the ecological services that trees provide their land and agricultural yields. 
A species-by-species breakdown of trees employed by the project at the time of this study follows:

Kajou Venezwela/Kajou etranje (Swietenia macrophylla)- One of the most popular trees in the project is a type of mahogany known as kajou venezwela and kajou etranje, which was introduced from Central America and has naturalized in the wetter regions of Haiti. Though a similar species known as kajou peyi (native mahogany, Swietenia mahagoni) or West Indian mahogany is native to Hispaniola and the Western Caribbean, kajou etranje offers "expanded opportunities for agroforestry and lumber production" and is a natural choice for the project (Timyan 1996: 47). Bwa Kapab (Colubrina arborescens) - The other popular wood species used in the project is bwa kapab and bwa ple, which is known in the United States as a Snake Bark or Snake wood tree. Known for its ability to produce straight and true poles popular in rural house construction, this species is native to Haiti and is particularly common around the humid coastal plains near Cap-Haïtien. It is extremely fast growing, provides excellent shade because of its large leaves and is easily propagated, all of which make it ideal for the project in Borgne (Timyan 1996: 13). Kakawo (Theobroma cacao)- Transitioning from wood trees, the only species that participants must technically purchase from the project is kakawo or cacao trees. Despite the fee, which is only 1 goud (or about 2.5 U.S. cents), the benefits to the owner are long term as the beans of the kakawo tree are used to make cocoa powder and chocolate - both of which can be sold at market or locally consumed (Timyan 1996: 181).

Chadè (Citrus maxima) - Though Columbus likely brought citrus fruit to Hispaniola 
during his second voyage in 1493, it was Captain Shaddock (hence chadè) who first introduced the grapefruit or pummelo variant to the Caribbean. His legacy lives on in Haiti as part of the agricultural system and livelihood of almost every Haitian cultivator. Beyond simply providing fruit, this species is popular in Haiti (and thus with the project) for its medicine, shade, extremely hard wood and flavor in Haitian cuisine (Timyan 1996: 96-98). The project uses two varieties of chadèk, one of which is slightly more "native" or naturalized to Haiti and one of which was introduced as part of PADF's work around Borgne.

Papay (Carica papaya) - The final species that was being distributed at the time of this study was the papay or papaya tree. Most popular for its sweet fruit, the papay is often made into juice or simply seeded and consumed. The papay also provides traditional healing benefits and is frequently used medicinally in Haiti. (Gooding 1973: 70).

On a final note about species, the project managers take great pride in the use of locally found species of trees, as well as the purchase or recycling of seeds from local sources. All seeds that are not taken from local sources in Borgne are purchased at markets in either Cap-Haitien or the nearby community of Port-Margot (just over $50 \%$ of seeds are purchased). Additionally, the organizations hope to begin a grafting program as well as to expand the type of fruit trees they provide to include mango, avocado, sweet orange and lime.

\section{IVe. Education, Distribution, Monitoring}

Twice per year, when the seedlings planted in the nursery are close to maturity, a day is selected to announce the project's intentions to distribute trees. On 
the day of the announcement, a large meeting is held in the neighboring town of Dumas (just west of the town of Borgne). The meeting is held here because of the more central location and accessibility to the rural areas surrounding the two communities. Attendance at the meetings is usually a few hundred people. Some attendees are organizationally affiliated, or work with gwoupman, but some are not. Trees are provided to all residents without discretion.

The agenda at the meetings is relatively simple but important. First, the logistics and date seedlings will be available to residents for pick up from the nurseries is announced. Second, an educational talk on the importance of trees and their benefits to both the environment and project participants is given. Finally, any additional questions from interested participants are fielded.

The next step in the process is distribution day, when project participants visit the nurseries to select their now mature seedlings. A demonstration on how trees should be planted, watered and cared for is given. Additionally, techniques are illustrated on how to help trees survive the initial planting phase-which is the most difficult. This might include the way in which a basin might be dug around the tree to aid it in catching more water or the way in which leaves or grass can be use to provide protection from the sun.

Following the demonstration, participants select about 25-30 trees to plant on their land. They are permitted to choose whatever species of tree they prefer. Though all other trees are provided free of cost, Cacao trees are provided for the cost of 1 goud (about 2.5 cents) because of their extreme value to the owner upon maturation. All of those who participate in the project, along with the number of trees 
they take, and the species, are recorded in a master list for the purposes of later observation. This list is broken down by the geographic location of the participant's residence and/or agricultural plot. After distribution, participants are free to plant trees at whatever location they desire.

Two to three days following the distribution of seedlings, the project's twelve monitors complete the first round of seedling visits and observation. The first round of observations, which is critical because of the fragile nature of the young seedlings, principally checks that the participant has properly planted the seedlings (or planted the seedlings at all). The number of seedlings taken by the participant is noted and checked against the number of seedlings planted. The planting location of the seedlings, whether at the participant's residence or at their plot, is also verified. Additionally, location of each seedling is observed to verify proper sunlight and that the bag in which the seedling was grown and transported has been discarded. The monitor also discusses the way in which the participant planted the tree, verifying the techniques described in the seminar to allow for water catchment and protection from excessive sunlight. Having verified and noted all of this information, the first visit is complete. If a participant has not yet planted the seedlings, the name is noted and following a stern warning, the monitor notes that he will return tomorrow to be sure the seedlings have been planted. If the seedlings have not been planted, he will take them back to the nursery (this does not seem to be a common occurrence however).

Each monitor employed by the project is designated to about 30 project participants based on geographic location (findings suggest between 300-400 participants in total). Monitors are also trained by an agronomist in both the general 
health of trees and the techniques for ensuring their proper maturation in the context of the project. After the initial monitor visit a few days after the seedlings have been planted, a monitor visits the trees each month for the following three months to ensure their good health and to collect data on the survival rates of the seedlings. Monthly reports on the status of the seedlings are also compiled. Following the threemonth period, the trees are healthy enough to survive on their own and further monitoring is not necessary.

\section{IVf. An Advantage of Fickle Funding?}

Funding for the tree-planting project in Borgne comes from the aforementioned American NGO (HOPE), who provides funding directly to the community organizations that run and manage the project. The budget varies based on the number of trees that are desired, as well as seed costs and other variable cost factors. During the period of this study, the total cost to run two nurseries that produce seedlings twice per year was between $\$ 6,000-7,000$. In addition to paying the wages of each of the project's employees, these numbers also cover the costs of all seeds, tools and other materials necessary for the project.

It is worth noting that HOPE has not provided funding for the project every year since its inception. Beyond the disadvantage in not providing trees, these breaks in funding and project operation illustrate the relative advantage of a "backyard" type of project that is flexible and adjustable to local conditions or fickle funding. Though breaking the "economies of scale" idea discussed as an advantage in the professionally run nurseries of the AOP, a smaller-scale project is not subject to a large donor or the bureaucratic whims of a more sizeable NGO. 
An additionally unique part of this project, particularly in the larger context of Haitian development, is the fact that it is entirely operated, managed and maintained by Haitians, in Haiti, from the community in which the project operates. With funding as the one exception to this rule, the use of local knowledge that local community organizations employ in running their own project trumps the fact that funding for the project is from an outside entity. Working directly with MODIEB and OGPK, HOPE can cater to their own needs or constraints without sacrificing their long-term goal of providing the means to plant trees in Borgne.

By the Numbers (estimated survival rate between 60-65\%)

\begin{tabular}{|l|l|}
\hline Year & Number of Trees \\
\hline 2006 & 8,000 \\
\hline 2007 & No Funding \\
\hline 2008 & 13,5000 \\
\hline 2009 & No Funding \\
\hline 2010 & $\begin{array}{l}\text { Several thousand trees } \\
\text { were distributed } \\
\text { during the period of } \\
\text { this study, with more } \\
\text { expected in } \\
\text { September of 2010 }\end{array}$ \\
\hline
\end{tabular}

\section{IVg. Situating Seedlings}

In examining the tree-planting practices and planters employed by local residents of Borgne that participated in the project, a diverse number of agroforestryoriented practices emerge. In addition to the general practice of mixing trees into existing agricultural systems, project seedlings were also specifically planted in erosion prone areas, around living spaces (lakou) and in spaced-out patterns that 
seemed to imitate forest patterns (I believe this was an effort to maximize their ecological benefit). These will be explored case-by-case based on the technique employed and the desired benefits of each practice in the context of Haiti.

Perhaps indicative of the extensive amount of indigenous knowledge described by White and Jickling (1995), many of the tree-planting and agroforestry practices of the project's participants do not fall into the category of any one specific technique. Instead they are a fusion of pragmatism and experience that maximize the use of each seedling. No one technique was dominant as all kinds of techniques were observed on the 20 or so farms that were visited throughout the course of research.

The first technique widely employed was the use of trees for boundary planting, to serve as a living border to delineate the end of property. This technique was also employed however with erosion-control in mind. Several participants frequently planted trees in a line where a ridge marked the end of the lakou and a steep slope either downward or upward began. This practice would seemingly reinforce the area around a living space to project it from erosion, flooding or wind (it might fall under the category of a "windbreak"). This was further evidenced by the trees that were planted directly into the grooves present from where rainwater had flowed out of the living area or down the hillside.

Another technique that was more common away from living areas was simple inter-cropping or what might be described as "Taungya" (Menzies 1988: 361). Young seedlings were planted with already mature crops (in some cases plantain trees) with the expectation that as they matured they would be moved to a more desirable location or the plot might be converted to another type of crop (the new 
shade might be conducive to growing coffee or cocoa). Under this scenario a symbiotic relationship forms between the already present crops and the newly planted seedlings.

Finally, seedlings were also distributed evenly in a bare spots on a given plot as to emulate a natural distribution pattern. Even distribution maximized the ecological service of the tree, allowing for an equal sharing of resources (rain and sunlight), while also holding the maximum amount of soil in place and allowing plenty of room for maturity. This again might allow for a plot to be converted to coffee, cocoa or other shade-tree crops to be grown.

While numbers and techniques are important, it is perhaps the model itself that is more important. The implications of this model will be explored at length in the following chapter. 


\section{Chapter V: Trees for the Future: Moving Beyond Preserving Borgne's Trees}

"If ever there were a society that ought to have ended up totally annihilated, materially and spiritually, by the trials of 'modernization,' it is Haiti." - Sidney Mintz (1972: 7)

\section{Va. A Haitian Project, and in Haiti}

Despite their fierce and independent origins as the world's first Black Republic, Haiti's history has been one of being subject largely to the whim of foreign powers (see Farmer 1994). While this has shifted from historic colonial endeavors aimed at mercantilist exploitation to the current presence of a robust United Nations peacekeeping force and the often-cited 10,000 international NGOs, Haiti continues to share all of humanity's desire to sing in the glory of self-sustaining sovereignty.

In spite of this desire, the current state of many development efforts in Haiti continues to be characterized by the presence of blan (foreigners). Though a historic trend, this is particularly relevant in the context of the millions of dollars, aid workers and good intentions that were sent to Haiti following the January 2010 earthquake that rocked Port-au-Prince. All of this being said, one cannot deny the presence of foreign entities engaged in what should be the goal of any development organization, to work itself out of the job. Further, while certainly two of the organizations cited in this study, SOIL and HOPE, are examples of this, it is clear that they almost certainly represent the exception and not the rule (see Schwartz 2008).

With these facts in mind the profound meaning behind a tree-planting initiative that is entirely local except for its funding becomes clear. Given the flexibility of currency, which can be used for the desired purposes of the 
organizations that control it, the bumbling awkwardness of an outsider trying to learn a new environment, new land, conditions, circumstances, language, etc. can be bypassed in favor of community level organizations that are already inherently familiar with the goals, needs, conditions and desires of those whom the project seeks to serve. The act of engaging then with the local and pre-adjusted civil society that already exists is favorable to the practice of larger organizations who often use a brush that paints broad strokes and seeks to find a general (in some cases countrywide) solution to development issues. This is, of course, the situation that often plagues larger organizations that have bureaucratically grown beyond their ability to adapt simply to the local conditions (see Bunch 1995).

Thus, the practices of HOPE to work directly with MODIEB and OGPK to engage in an environmental initiative like the tree-planting project profiled in this study, represents an important model of the ways in which NGOs can engage in development efforts. With that acknowledged however, given that the primary architect of the current project in Borgne was trained by PADF as an informateur, the current tree-planting project in Borgne would not be possible without the dissemination of the skills provided by the AOP (which, as previously mentioned represents the largest and most robust effort to plant trees in Haiti). When viewed through AOP-tinted glasses, one might label Borgne's current project as a long-term extension of the AOP, though perhaps it is a better example of the importance of extension education and the long-term impact that the efforts of training a few key individuals can have on a community, society or nation. 


\section{Vb. Differing Goals: A Comparison}

If from a macro level Borgne's project can be viewed as a successful example of adjusting to local conditions, engaging local civil society and completing grassroots development in general, then it is from the micro level that the crux of its criticism can be found.

When isolated from the larger flux of tree-planting efforts, the simple act of planting a few thousand trees by a local organization is commendable in its own right. However, when that same act is viewed within the larger context of the tree-planting efforts undertaken by robust NGOs, international organizations and governments, who are capable of producing millions of trees through professionally run nurseries, it shrinks in significance. This of course falls into the same vein as the argument made by Murray and Bannister against the type of small-scale "backyard nurseries" that are the keystone of the project in Borgne. At their zenith, the 36 professionally run nurseries of the AOP were capable of producing nearly 10 million trees per year (or with some basic arithmetic, an average of about 275,000 trees per nursery) (Murray and Bannister 2004: 385). One can compare this number to the current nurseries in Borgne, which are capable of producing at maximum 35,000 seedlings per year (though in reality significantly fewer seedlings are produced due to funding limitations). Though the quality of seedling and survival rate, along with copious other factors can be considered, strictly by the numbers it cannot be denied that the professionally run nurseries of the AOP far outshine the smaller scale "backyard" type of nurseries that are at work in Borgne.

However, a comparison that moves beyond simply juxtaposing the numbers 
reveals that while the argument that "economies of scale" and "quality control" favor professionally run nurseries, it fails to acknowledge the unique factors at play in Borgne and the differing goals of the respective projects. As previously mentioned the AOP represents a large, well-funded effort that reached "300 000 Haitian peasant households - over a third of the entire rural population of Haiti - to plant wood trees as a domesticated, income-generating crop on their holdings" (Murray and Bannister 2004: 383). Comparing this to the project in Borgne, whose target population is only the 80,000 or so people that live within the section, reveals that based on target population alone a large gap exists within the goals of the projects.

While a difference in the populations in question exists, the rate of production of the professionally run nurseries also may have been too efficient for the Haitian setting. At its outset the AOP provided project participants with 500 seedlings but "labor constraints (more so than land constraints) made it difficult for many farmers to plant 500 seedlings at one fell swoop, since the planting of seedlings had to be timed with rains, which was the trigger for planting other crops as well" (2004: 386). The number of seedlings provided by AOP was eventually lowered to 200 per participant. Yet, beyond the simple problems of labor in planting such a large number of trees, providing even 200 seedlings would seem to incentivize carelessness, and might roughly be equated with the basic economic principle of diminishing marginal utility. In comparison, the project in Borgne provides 25-40 seedlings to each participant. Ideally this happens twice per year during each rainy season (for a total of 50-80 trees per year). These numbers are much more manageable for participants and seem to take into consideration both the value of 
trees and the necessary labor to effectively plant and manage a decent number of seedlings.

Another reason for this significant gap in numbers might be the desired outcome of the trees being planted. The stated goal of the AOP to provide "wood trees as a domesticated, income-generating crop" is much different than the current project in Borgne, which specifically provides trees to its participants that encourage long term planting without shorter-term cutting — such as fruit trees or other wood species that favor construction material over use as charcoal fuel (see Chapter 4 for a species list) (2004: 383). Beyond the encouragement of long term planting, the employment of fruit species also favors both a longer-term food source, income generation in the market or both.

When examined from a more holistic environmental perspective, the selection of these types of trees also favors the goal of the project to reinforce the already existing tree-covered landscape that dominates the mountains surrounding Borgne. A tree-heavy climate is believed to favor rainfall and even on a more macro level is indicative of a healthy ecosystem that manages water, the health of the soil, air, and is more favorable to the agricultural endeavors that drive the local economy. These large-scale, overarching ideas stand in sharp contradiction to the AOP's goal of providing wood trees as an income-generating crop that are planted with the intention of being felled at some point by their owner. This is not to disparage the AOP's design, which, unlike previous tree-oriented projects in Haiti wisely acknowledged the inability to "reforest" Haiti and view trees solely for their environmental or “conservationist" values: 
The earliest reforestation attempts were emphatically not happy stories. They began under foreign prodding with the arrival of development agencies after World War II. These early projects were largely based on the theme of reboisement, protectionist and conservationist reforestation premises inappropriate to a virtually treeless but densely inhabited country. (Murray and Bannister 2004: 384)

Thus it is apparent that though the AOP's design accounts for general conditions in most of rural Haiti, there are specific instances that deviate from the norm. For example, the generalization that Haiti is "virtually treeless" does not account for exceptions to the rule where trees still dominate the landscape and may have a large enough impact on the local climate to favor a conservationist tree-planting approach over the AOP's approach which treats the tree as a crop to be felled, wholly ignoring the trees larger environmental impact (Borgne might serve as an example of this, along with other areas that retain significant forest cover). This is not to criticize the AOP on the whole; rather it is to illustrate the flexibility of a smaller-scale, local project that need not be planned around generalized, grandiose categories.

Finally, it must be noted that it may be somewhat unfair to compare the AOP and the current project in Borgne as the two projects must be viewed from a linear perspective rather than as concurrently designed projects (that is to say it can be argued that one significantly affected the other). With that acknowledged however it is still a useful exercise if for no other reason than it illustrates the differences, strengths and weaknesses of a project that can cater to local conditions versus one that is implemented on a much wider, more general scale. 


\section{Vc. Another Level of Analysis - The Yardstick}

"It is understandable that the rational talents on this side of the world, exalted in the contemplation of their own cultures, should have found themselves without valid means to interpret us. It is only natural for that they insist on measuring us with the yardstick that they use for themselves, forgetting that the ravages of life are not the same for all."

-Gabriel Garcia Marquez (1995: 135)

Removing for a moment, the cap of analysis that seeks to measure success based on the traditional governing principles of the nations that engage in the northto-south pattern that dominates modern development efforts, the current project in Borgne and its relative success can be viewed from an entirely different perspective. While the number of trees that are planted, the soil they hold into place and the benefits they provide farmers are of the utmost importance, there is also a significant value in the non-tangible cultural preservation that the project represents. Indeed as Hirschman (1984) describes, grassroots development in itself rejects the "worship of 'gross national product' and of the 'end rate of growth'" instead focusing on the overall impact that is does not need to be "reassured at every step by optimistic reports on the macroeconomic consequences of their work" (Hirschman 1984: 95).

As has been extensively discussed throughout this study, the dynamic factors at play in Borgne have produced a unique culture of environmentalism that pervades through every aspect of the community. Though the presence of gwoupman and the AOP are significant factors in this phenomenon and represent the influence of foreign entities, Borgne's relative isolation from the rest of Haiti, and the community's ability 
to maintain many of their natural resources in the form of valuable trees are also significant factors. When viewed through this lens, the rich pockets of tree-cover that remain in Borgne are tantamount to the community's civic and cultural identity. As such, the current tree-planting project can be viewed as an effort not just to plant trees but also to preserve the keystone of Borgne's civic and cultural identity.

This idea sheds new light on the project and also significantly alters the idea of the "success" of the project. Despite being inherently influenced by large organizations engaged in global development efforts such as USAID and the Catholic Church — and being tied to foreign entities through funding for their work via HOPE - the fluid concept of culture allows space for evolution. Combining this space with geographic distinction and the continued evolution of dynamic community organizations has produced the current tree project. From this perspective success takes on an entirely new definition and regardless of the number of trees planted by the organizations, the decision to engage in such a project represents success.

\section{Vd. Implications throughout the Island}

Given the current number of foreign organizations operating in Haiti and the renewed attention from the international community following the January 2010 earthquake, it can safely be assumed that just as thousands of trees have been planted in Haiti in the past, thousands more will be planted in the future. Who will undertake this work remains unclear though it is worth noting that there are hundreds of smaller organizations already engaging in "reforestation" projects (the simplest Google search reveals this). Given that trees will continue to be planted by NGOs, International Organizations and perhaps even Haitian government agencies, there is 
great value in the existence of a viable community-oriented model such as the one employed by the organizations operating the current project in Borgne.

This is not to say that one model fits all, rather that certain aspects of the project ought to be replicated or incorporated by other organizations with similar goals of providing trees to the communities in which they work. This is not limited to Haitian organizations as HOPE's model of profound community engagement is admirable and ought to be at the very least examined by other organizations in Haiti. By providing the means to engage in a project rather than the personnel, staff, materials, etc. they have enabled the unique civic culture that characterizes Borgne to continue unabated, all the while providing jobs that do not subtract from the important work of aiding the local community. Even more can be said however, for the community organizations already at work in Borgne. Their work will continue and they will grind forward tet ansanm (heads together) with or without the support of foreign entities. It boils down then to cooperation, the willingness on HOPE's part to engage with the civil structures that already exist and the will of the community organizations to continue their work in partnership.

In closing, it is my humble hope that in some way this study will contribute to the development of such important projects - and further, that those projects will come to reflect the dynamism of the community organizations at work in Borgne and throughout all of rural Haiti. 


\section{LIST OF REFERENCES}

Arthur, Charles and Michael Dash, eds. A Haiti Anthology: Libète. Latin American Bureau, Ltd. London, 1999.

Balzano, Anthony. "Socioeconomic Aspects of Agroforestry in Rural Haiti." University of Maine Agroforestry Research Component. Agroforestry Outreach Project. Port- auPrince, Haiti: USAID. 1986.

Bernard, H. Russell, Ed. Handbook of Methods in Cultural Anthropology. Walnut Creek, CA: AltaMira Press. 1998.

Bookchin, Murray. Post-Scarcity Anarchism. Berkeley, California: Ramparts Press, Inc. 1971.

Bray, David Barton. 2009. "40 Years of Getting Ahead Collectively: What the Big Development Thinkers Ignore." pp. 2-9. Grassroots Development 30, no. 1.

Bunch, Roland. "People-Centered Agricultural Development: Principles of Extension for Achieving Long-Term Impact.” pp. 145-155. World Bank Symposium. Agriculture and the Environment. Edited by Ernst Lutz. Washington D.C.: The World Bank, 1998.

Bunch, Roland. Two Ears of Corn: A Guide to People-Centered Agricultural Improvement. Oklahoma City, Oklahoma. World Neighbors, 1982.

Crang, Mike and Ian Cook. Doing Ethnographies. London. Sage Publications Limited. 2007.

Farmer, Paul. The Uses of Haiti. Monroe, Maine: Common Courage Press. 1994.

Gooding, E.G.B., Wayside Trees and Shrubs of Barbados. London. Macmillan Education Ltd., 1973.

Hirschman, Albert O. Getting Ahead Collectively: Grassroots Experiences in Latin America. New York: Pergamon Press. 1984.

Homer-Dixon, Thomas F. 1994. "Environmental Scarcities and Violent Conflict: Evidence from Cases." International Security. 19:1 (Summer) 5-40.

H.O.P.E.: About Borgne Haiti. Haiti Outreach: Pwoje Espwa. www.hopehaiti.org (December 18, 2010) 
Jickling, Jon L. and Thomas A. White. "Economic and Institutional Analysis of Agroforestry Projects in Haiti." pp. 176-194. In World Bank Paper 14. Costs, Benefits, and Farmer Adoption of Agroforestry. Edited by Dean Current, Ernst Lutz, and Sara Scherr. Washington D.C.: The World Bank, 1995.

Kramer, Sasha. 2010. SOIL: What We Do. Sustainable Organic Integrated Livelihoods. http://oursoil.org (September 25, 2010).

Locher, Uli, Glenn R. Smucker and Drexel G. Woodson. "Comparative Evaluation of Three Rural Development Projects.” Executive Summary. USAID/Haiti. October, 1983.

Lundahl, Mats. Politics or Markets? Essays on Haitian Underdevelopment. London. Routledge, Chapman and Hall, Inc. 1992.

Maguire, Robert. Bottom Up Development in Haiti. Washington, D.C. Inter-American Foundation, April 1981.

Maguire, Robert. "Special Report 232: Haiti After the Donors Conference." Washington D.C. United States Institute of Peace, September 2009.

Marquez, Gabriel-Garcia. "The Solitude of Latin America." Nobel Lecture (December 8, 1982). Georgia Review 45 (1): 133-36. 1995.

Menzies, Nick. "Three Hundred Years of Taungya: A Sustainable System of Forestry in South China." Human Ecology. Volume 16, No. 4: 361-76. December 1988.

Mintz, Sidney. Introduction. In Alfred Metraux Voodoo in Haiti, pp. 1-14. New York, Schocken. 1972.

Murray, Gerald F. and M.E. Bannister. 2004. "Peasants, agroforesters and anthropologists: A 20-year venture in income generating trees and hedgerows in Haiti." Agroforestry Systems. 61: 383-39.

Schwartz, Timothy. Travesty in Haiti: A true account of Christian missions, orphanages, fraud, food aid and drug trafficking. Charleston, South Carolina: Booksurge Publishing. 2008.

Shacochis, Bob. The Immaculate Invasion. New York, New York. Penguin Books, 1999.

Smith, Jennie M. When the Hands are Many. Ithaca, New York. Cornell University Press, 2001.

Smucker, Glenn R. T. Anderson White and Michael Bannister. "Land Tenure and the Adoption of Agricultural Technology in Haiti." Collective Action and Property Rights Working Paper No. 6. June 2002. 
Tarter, Andrew. 2009. Thirty Years After A Tree-Planting Project: A Political Ecology Perspective on Behavior and Land Changes in Rural Haiti. MA Thesis: University of Florida, Gainesville, FL.

Timyan, Joel. "Bwa Yo: Important Trees of Haiti." South-East Consortium for International Development. Washington, DC. 1996.

Vannier, Christian N. "Audit Culture and Grassroots Participation in Rural Haitian Development." PoLAR: Political and Legal Anthropology Review. Vol. 33, No. 2 (November) 282-305. 2010.

White, T. Anderson. "Policy Lessons from History and Natural Resource Projects in Rural Haiti." Environmental and Natural Resources Policy and Training Project (EPAT) Working Paper No. 17. November 1994.

White, T. Anderson and C. Ford Runge. "The Emergence and Evolution of Collective Action: Lessons from Watershed Management in Haiti." World Development. Vol. 23, No. 10. Pages 1683-1698. 1995.

White, T. Anderson, and Jon L. Jickling. "Peasants, experts, and land use in Haiti: lessons from indigenous and project technology." Journal of Soil and Water Conservation 50.1 1995(b).

Whyte, William Foote. Participatory Action Research. Newbury Park, California, USA: Sage Publications Incorporated, 1991.

World Factbook. Country Report: Haiti. https://www.cia.gov/library/publications/theworld-factbook/geos/ha.html (March 18, 2011). 